\title{
Performance of a Nano Pbs/Si Hetrojunction Deposited By Chemical Spray Pyrolysis
}

\author{
Ali M.Mousa, Karem H. Jawad \\ Department of Applied Sciences, University of Technology, Baghdad, Iraq
}

(Received 28 May 2015; published online 29 August 2014)

\begin{abstract}
Deposition of polycrystalline Lead sulfide nano thin films onto Si and glass substrates at temperatures $\left(200-300^{\circ} \mathrm{C}\right)$ was carried out by chemical spraying route using optimized preparative conditions. The XRD pattern confirmed the formation of $\mathrm{PbS}$ semiconducting films with orthorhombic structure. The electrical and optical properties of the nano crystalline thin films were studied aiming to better understanding for the electrical and opto-electrical properties of a hetrojunction with p-type Si. It was found that, the average grain size of $\mathrm{PbS}$ in the films was between $4 \mathrm{~nm}$ and $7 \mathrm{~nm}$. The band gap was also calculated from the absorption co-efficient curves and showed a blue shift due to the grain size of the nano PbS in the films. The current-voltage (I-V) and photoresponse characteristics were obtained with different illumination intensities. The detector exhibits an evident wide-range spectral responsivity.
\end{abstract}

Key words: Nano film, hetrojunction, chemical spray pyrolysis deposition.

PACS numbers: $61.46 . \mathrm{Hk}, 81.07 . \mathrm{Bc}, 85.35 . \mathrm{Be}$

\section{INTRODUCTION}

Quantum confinement in nanosemiconductors (which occurs when electrons are strongly confined in one, two or three dimensions), is the basic behind research and development of low-dimensional semiconductor nanostructures .It had been theoretically and experimentally [1-3], demonstrated that semiconductor quantum wires and dots, where electrons are confined in two and three dimensions respectively, can provide a significant additional enhancement of device performance due to [4] (1) blue shift in photoluminescence, (2) energy levels of core bands and the adsorbater-induced satellite shift simultaneously towards higher binding energy, (3) dielectric constant is suppressed and causes a blue shift in photo absorption. $\mathrm{PbS}$ is one of the best known chalcogenides enjoying an increasing interest due to their specific properties, such as band gap enlargement, quantization of the electronic levels, that make them attractive for opto-electronic applications. A variety of techniques have been reported for nanostructures synthesis, among them, chemical spraying pyrolysis method, considered as the most suited for thin film deposition because it allows the size and composition of the nanostructures to be varied, flexibility to use a variety of substrate materials, and does not require sophisticated and costly equipment of deposition [5-7]. Here, we present a heterojunction, based on $\mathrm{Si}$ and $\mathrm{PbS}$ nanoparticles, fabricated in the $\mathrm{Al} / \mathrm{PbS} / \mathrm{Si} / \mathrm{In}$ architecture, where the nanoparticle films are deposited by spray pyrolysis from solutions.

\section{EXPERIMENT}

Silicon and glass are used as a substrate for Nanostructures pbS thin films deposited bychemical spray pyrolsis method. The CSP method has been chosen in this work because the method is economical, requires short processing time, can be performed in atmospheric conditions and can prepare thin films. Silicon wafers used for fabricating $\mathrm{PbS} / \mathrm{Si}$ heterojunction were p-type (111) orientation with resistivities of (1.5-4
$\Omega \mathrm{cm})$ and $(500 \mu \mathrm{m})$ thickness. They were rinsed in acetone and ethanol in order to remove dirt and oil, while native oxide layer was removed by etching in dilute (1:10) $\mathrm{HF}: \mathrm{H}_{2} \mathrm{O}$ solution. The nano $\mathrm{PbS}$ layer was deposited from a solution having optimal deposition $\begin{array}{lll}\text { parameters including } \mathrm{pb}(\mathrm{NO} 3)_{2} & (0.01 \mathrm{M}) \text {, }\end{array}$ $\mathrm{CS}(\mathrm{NH} 2)_{2}(0.01 \mathrm{M})$. Bath temperate of $\left(300^{\circ} \mathrm{C}\right)$ and the total deposition time of $90 \mathrm{~min}$. The film deposition temperature was measured from the glass surface when de ionized water was sprayed. Electrodes were deposited on both sides of the $\mathrm{PbS} / \mathrm{p}$-Si. Ohmic contacts from high purity aluminum wire $5 \mathrm{~N}$ with $200 \mathrm{~nm}$ thicknesses onto the back surface of $\mathrm{Si}$, and indium on $\mathrm{PbS}$ layer were performed through a metal mask. Dark current-voltage $\mathrm{PbS} / \mathrm{Si}$ measurements were carried out by applying a voltage to the sample from a stabilized d.c. Fine power supply, type L 30-2 Farnell of range $(0.1-5) \mathrm{V}$. The current passing through the device was measured using a Keithley (602) electrometer. Capacitance-Voltage characteristics of the heterojunction were measured using a PM 6306 Programmable LRC meter supplied by Fluke. The reverse bias voltage ranged from $(0.5-5) \mathrm{V}$. The junction type (abrupt or graded) and therefore the built - in potential $\mathrm{V}_{b i}$ were determined from intercept at $1 / \mathrm{C}^{2}=0$ by extrapolating the curve to the voltage axis. The spectral responsivity of the $\mathrm{PbS} / \mathrm{Si}$ heterojunction was measured using a monochromator with spectral range of (360-1000) nm. Power calibration was established using a standard power meter. This measurement was performed with a reverse bias $(1 \mathrm{~V})$. The Responsivity $R_{\lambda}$ and quantum efficiency were calculated. Rising and decay time of the photocurrent were measured using a halogen lamp.

\section{RESULTS}

\subsection{Hetrojunction Characteristics}

Fig. 1 shows the current-voltage (I-V) characteristics of PbS nano films grown on p-Si (100) substrates at room temperature. This I-V curve indicates that the $\mathrm{PbS} / \mathrm{Si}$ (100) heterostructures have rectification proper- 
ties. Table 1 shows the saturation current, ideal factor of the heterojunction. An ideality factor greater than unity is generally attributed to the interfacial oxide layer [12], suggests that current transport is influenced by space charge recombination.

Table 1 - Shows the heterojunction parameters.

\begin{tabular}{|c|c|c|c|c|}
\hline \multirow{2}{*}{\multicolumn{2}{|c|}{$\beta$ Factor }} & \multicolumn{3}{c|}{ Ideal deposition parameters } \\
\cline { 2 - 5 } \multicolumn{2}{|c|}{} & $\begin{array}{c}\text { Solution } \\
\text { molarity }\end{array}$ & Temperature & time \\
\hline 1.38 & 0.48 & $0.06 \mathrm{ML}$ & $300^{\circ} \mathrm{C}$ & $90 \mathrm{~min}$ \\
\hline
\end{tabular}

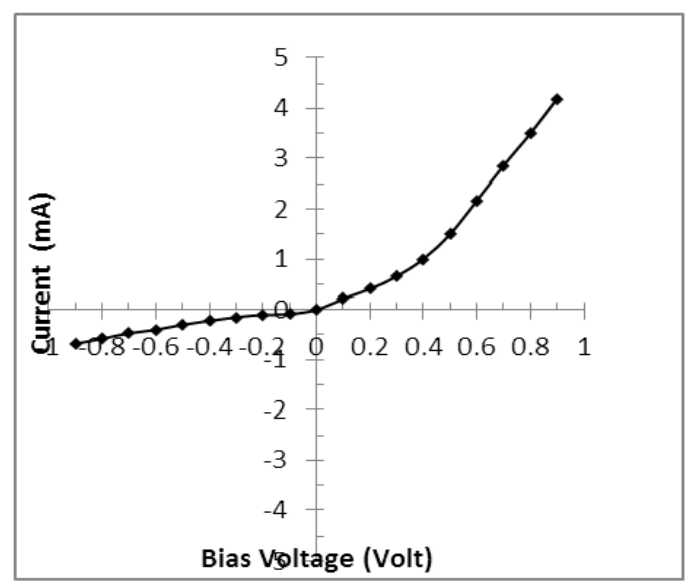

Fig. 1 - Shows the current-voltage characteristics

Capacitance and voltage $(\mathrm{C}-\mathrm{V})$ characteristics of $\mathrm{PbS} / \mathrm{Si}$ diode were measured using a PM 6306 Programmable LRC meter. The capacitance is expected to decrease with increasing reverse bias, due to an increase in the depletion region width. Thus, the voltage dependence shown in Fig. 2 is at least qualitatively consistent with the expected trend. Fig. 3 shows a plot of $1 / \mathrm{C}^{2}$ as a function of bias voltage. The plot of $1 / \mathrm{C}^{2}$ versus reverse bias voltage is linear and the intercept on the $\mathrm{x}$-axis is at the voltage $\mathrm{V}_{0}=\mathrm{V}_{\mathrm{bi}}-\mathrm{kT} / \mathrm{q}$, where $\mathrm{V}_{\mathrm{bi}}$ is the built-in potential, and $\mathrm{T}$ is the absolute temperature. The linearity in the plot of $\mathrm{C}^{-2}$ as a function of $\mathrm{V}$ indicates the uniform doping of depleted region and abrupt junction

Fig. 4 shows the hetrojunction photocurrents as a function of voltage under steady state illumination at different light intensity. The photocurrent monotonically increasing with incident light intensity, also the photocurrent shows no saturation at the voltage range. Fig. 5 shows the hetrojunction spectral responsively. It clearly proved that this material had very good photo response, where the maximum response exists at $\lambda=0.5-0.52 \mu \mathrm{m}$. For all wavelengths less than $0.5 \mu \mathrm{m}$, the responsively increases with increasing wavelength, while for longer wavelengths, responsively decreases with increasing wavelength. The hetrojunction quantum efficiency, with a quantum peak at $\lambda=520 \mathrm{~nm}$. the value is not constant across the entire spectrum of wavelengths measured, and shows a reduction in the value for all wavelength shorter and greater than 520 $\mathrm{nm}$.and this more probably due to recombination at the surface and in the bulk.

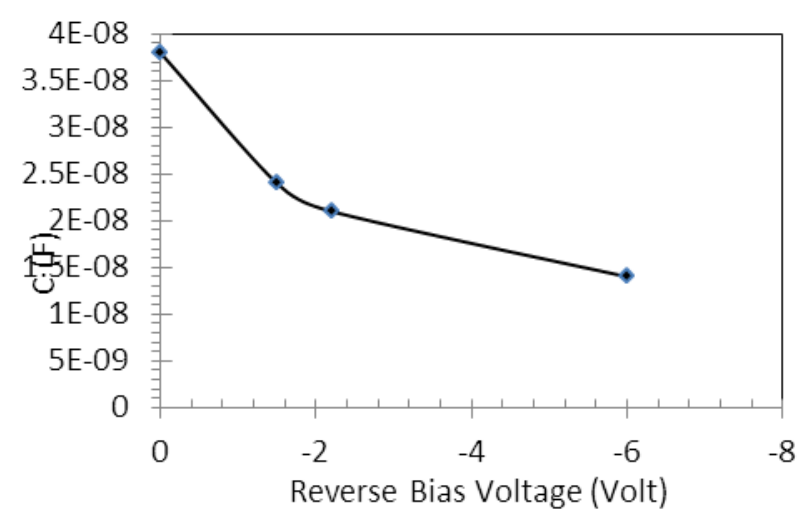

Fig. 2 - The voltage dependence of junction capacitance

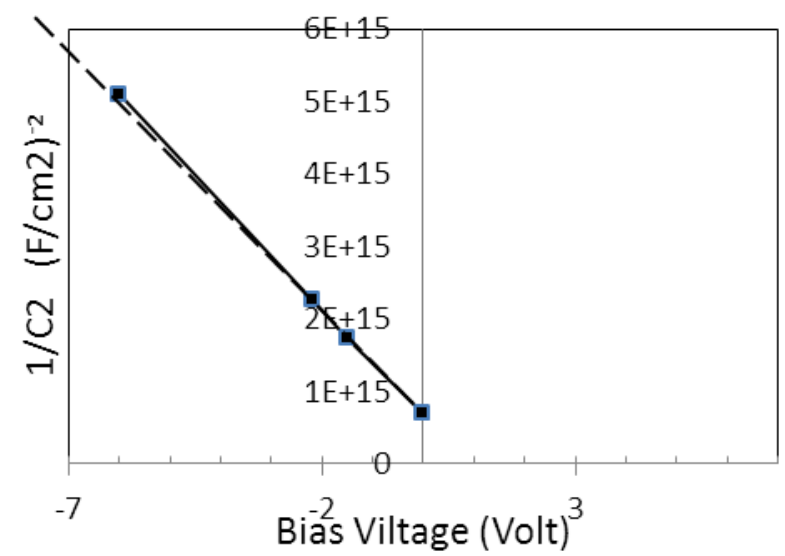

Fig. 3 - A plot of $1 / \mathrm{C}^{2}$ as a function of bias voltage

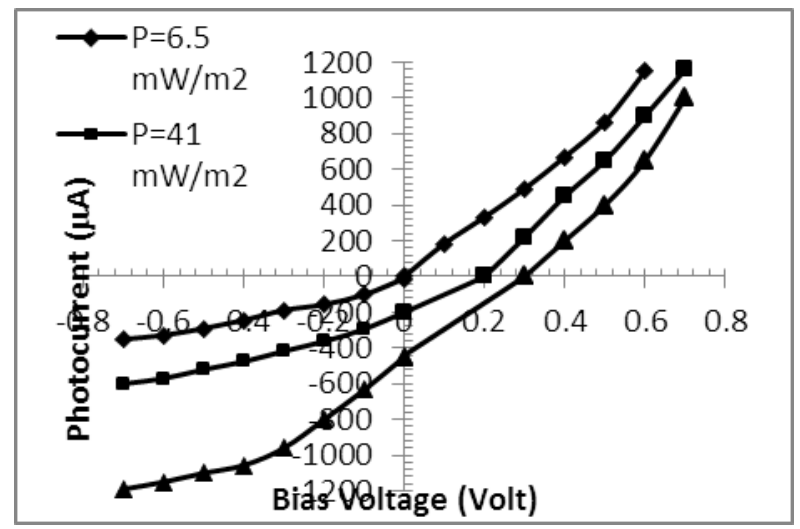

Fig. 4 - Hetrojunction photocurrents

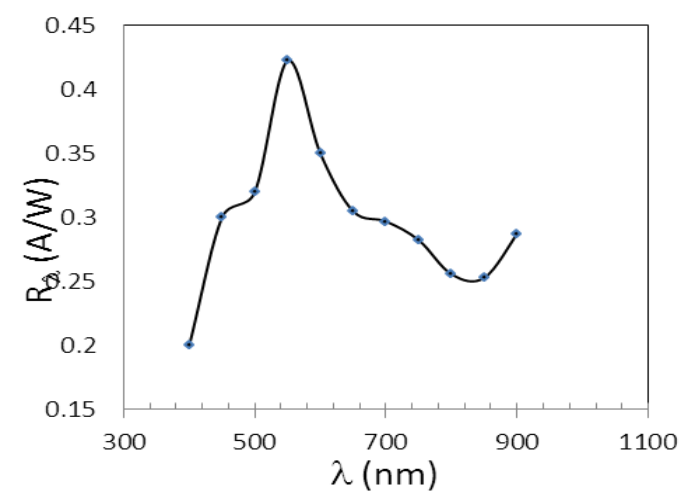

Fig. 5 - Hetrojunction spectral quantum efficiency 


\section{CONCLUSIONS}

Nano crystalline hetrojunction formed by deposited $\mathrm{PbS}$ on p-type Si by chemical spray pyrolysis. The best performance was obtained with $90 \mathrm{~min}$. deposition.

\section{REFERENCES}

1. K. Yu, J. Chen, Nanoscale Res. Lett. 4, 1 (2009).

2. V. Svrcek, A. Slaoui, J.C. Muller, Thin Solid Films 451452, 384 (2004).

3. Ali M. Mousa, and Adawiya J. Haider, J. Mat. Sci. Eng. A 1, 111 (2011).

4. C.Q. Sun, B.K. Tay, S. Li, X.W. Sun, S.P. Lau, T.P. Chen, Mater. Phys. Mech. 4, 129 (2001)
Photo-electrical measurements show a guessing response at wave range $0.4 \mu \mathrm{m} \leq \lambda \leq 0.9 \mu \mathrm{m}$ monotonically increasing with incident light intensity, a quantum peak at $\lambda=520 \mathrm{~nm}$.

5. A.M. Mousa, M.A. Mohammed, and R. Kadhim, AIP Proc. 1653, 020073 (2015).

6. Ali M. Mousa, Selm M. H. Al-Jawadi, Suad M. Kadhim AlShammari, Int. J. Semiconductor Sci. Tech. 3 No4, 11 (2013).

7. Lung-Chien Chen, Cheng-An Hsieh, and Xiuyu Zhang, Materials 7, 7304 (2014) 